\title{
Water splitting by Photosystem II-where do we go from here?
}

\author{
Thomas J. Wydrzynski
}

Received: 30 October 2008/Accepted: 10 November 2008/Published online: 27 November 2008

(C) Springer Science+Business Media B.V. 2008

\begin{abstract}
As this special issue shows, we know quite a lot about the workings of Photosystem II and the oxidation of water to molecular $\mathrm{O}_{2}$. However, there are still many questions and details that remain to be answered. In this article, I very briefly outline some aspects of Photosystem II electron transport that are crucial for the efficient oxidation of water and require further studies. To fully understand Photosystem II reactions is not only a satisfying intellectual pursuit, but is also an important goal as we develop new solar technologies for the splitting of water into pure $\mathrm{O}_{2}$ and $\mathrm{H}_{2}$ for use as a potential fuel source. "As Students of the Past, We Send Greetings to the Students of the Future."*
\end{abstract}

Keywords Photosynthesis · Photosystem II · $\mathrm{O}_{2}$ evolution $\cdot$ Water splitting $\cdot$ Future studies

$\begin{array}{ll}\begin{array}{l}\text { Abbreviations } \\ \text { (B)Chl }\end{array} & \text { (Bacterio)chlorophyll } \\ \mathrm{BRC} & \text { Bacterial reaction center } \\ \mathrm{Car} & \beta \text {-Carotene } \\ \mathrm{Chl} a, d & \text { Chlorophyll } a, d \\ \mathrm{Chl}_{\mathrm{D} 1}, \mathrm{Chl}_{\mathrm{D} 2} & \text { Accessory chlorophylls of the PSII RC } \\ \mathrm{ChlZ}_{\mathrm{D} 1}, & \text { Chlorophyll Z of the PSII RC } \\ \mathrm{ChlZ}_{\mathrm{D} 2} & \\ \mathrm{Cyt} b_{559} & \text { Cytochrome } b 559 \\ \mathrm{Cyt} c_{550} & \text { Cytochrome } c 550 \\ \mathrm{D} 1, \mathrm{D} 2 & \text { PsbA and PsbD proteins of the PSII RC } \\ \text { DFT } & \text { Density functional theory }\end{array}$

*The Alma Mater of the University of Illinois at Urbana-Champaign.

T. J. Wydrzynski ( $\square)$

School of Biology, College of Medicine, Biology

and Environment, Australian National University,

Canberrra, ACT 0200, Australia

e-mail: tom.wydrzynski@anu.edu.au
ECHT Environmentally coupled hydrogen transfer

ENDOR Electron nuclear double resonance

EPR Electron paramagnetic resonance

ESEEM Electron spin echo envelop modulation

EXAFS Extended X-ray absorption fine structure

FTIR Fourier transform infrared

KIE Kinetic isotope effect

LBHB Low-barrier hydrogen bond

$\mathrm{Mn}_{4} \mathrm{Ca} \quad$ Manganese/calcium catalytic site for the oxidation of water

MSP Manganese stabilizing protein

PSII Photosystem II

P680 Primary electron donor of the PSII RC

$\mathrm{P}_{\mathrm{D} 1} \mathrm{P}_{\mathrm{D} 2} \quad$ Chlorophyll dimer of the PSII RC

PCET Proton coupled electron transfer

Pheo $_{\mathrm{D} 1}$, Pheophytins of the PSII RC

$\mathrm{Pheo}_{\mathrm{D} 2}$

PQ Plastoquinone A

$\mathrm{Q}_{\mathrm{A}}, \mathrm{Q}_{\mathrm{B}} \quad$ First and second quinone acceptors respectively

QM/MM Quantum mechanics/molecular mechanics

RC Reaction center

RIXS Resonant inelastic X-ray scattering

ROS Reactive oxygen species

Sn Oxidation states of $\mathrm{Mn}_{4} \mathrm{Ca}$ for $n=0,1,2$, 3,4

XANES X-ray absorption near edge spectroscopy

$\mathrm{Y}_{\mathrm{Z}}, \mathrm{Y}_{\mathrm{D}} \quad$ Redox-active tyrosines of the PSII RC

\section{Introduction}

In 1972 when I began my Ph.D. studies with Govindjee at the University of Illinois at Urbana-Champaign the 
Photosystem II (PSII) electron transport chain was little more than a bunch of letters. The primary electron donor (P680) had been identified earlier by Witt and co-workers (Döring et al. 1969) as a special photo-active chlorophyll molecule having its major red absorbance difference band at $680 \mathrm{~nm}$. The intersystem electron acceptor pool was known to consist of 5-10 lipid-soluble plastoquinone A (PQ) molecules (Stiehl and Witt 1969) which become doubly reduced to plastohydroquinol $\left(\mathrm{PQOH}_{2}\right)$ by the electrons coming from the photo-oxidation of P680. The fluorescence quencher (Q) (Duysens and Sweers 1963) was determined to be a special protein-bound plastoquinone $\mathrm{A}$ molecule that is an electron acceptor which cycles only between the oxidized and semi-quinone states (van Gorkom 1974). Also by this time Joliot et al. (1969) had discovered the beautiful period four oscillations in $\mathrm{O}_{2}$ production and Kok et al. (1970) had just published their $\mathrm{S}$-state model of the $\mathrm{O}_{2}$-evolving component $(\mathrm{S})$, which has been a cornerstone of PSII research through today. An intermediate $(\mathrm{Z})$ between the S-state component and P680 was predicted from thermodynamic arguments and so in 1972 the PSII electron transport chain was given by the simple scheme below (Wydrzynski 1981):

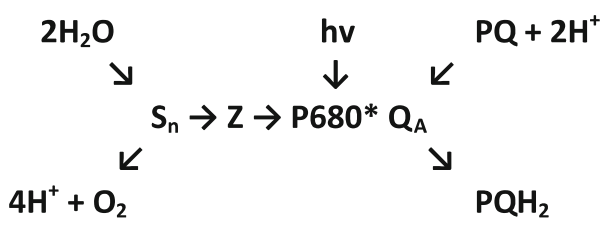

Over the last three decades since my Ph.D., I have had the good fortune to be part of the generation of researchers who have refined and identified the cofactors, electron transfer reactions, and protein components of the PSII complex that catalyzes the oxidation of water to molecular di-oxygen $\left(\mathrm{O}_{2}\right)$. We now know quite a lot about PSII structure and function at the molecular level, which is detailed in recent monographs (Wydrzynski and Satoh 2005; Renger 2008), special journal issues (Nugent 2001; Barry and Brucker 2002; Barber and Anderson 2002; Messinger and Lubitz 2004; Carpentier and Allakhverdiev 2005; Allakhverdiev et al. 2007; Putnam-Evans and Barry 2007; Brudvig 2008; Barber and Rutherford 2008; Eisenberg and Gray 2008), and this special issue of Photosynthesis Research. The minimal functional motif for oxidizing water in PSII is the following sequence of cofactors: a terminal plastoquinone electron acceptor; a photo-oxidizable chlorophyll/pheophytin acceptor complex; an intermediate redox-active tyrosine; and a tetra-nuclear manganese/calcium cluster that serves as the catalytic site (Wydrzynski et al. 2007). In the quest to model the PSII water oxidation reaction in artificial photosynthetic systems, it will be essential to understand those mechanistic features of PSII that optimize the functional motif. The following sections outline some of these mechanistic features that remain to be determined in future studies. The reader is directed to the above references for the details of the various arguments used in the following sections.

\section{Functional organization of Photosystem II electron transport}

Photosystem II consists of several different types of chlorophyll binding components (see Storm et al., this issue) whose function is to organize the chlorophylls for lightharvesting and a multi-subunit core complex that harbors the electron transport cofactors needed for the oxidation of water (see Iida et al., Tomo et al., this issue). Biochemical purification procedures and electron cryo-microscopy have shown that PSII core complexes associate as dimers within the lipophilic structure of the thylakoid granal membrane (Hankamer et al. 2001; see Anderson et al., Leng et al., this issue), while analysis by X-ray crystallography has revealed the basic arrangement of the electron transport cofactors within the core complex itself down to an atomic resolution of 3-3.5 $\AA$ (Fig. 1) (Loll et al. 2005; Ferreira et al. 2004). The relevant cofactors needed for the oxidation of water are: the chlorophyll dimer, $\mathrm{P}_{\mathrm{D} 1} \mathrm{P}_{\mathrm{D} 2}$; the accessory chlorophyll $a, \mathrm{Chl}_{\mathrm{D} 1}$; the primary electron acceptor pheophytin $a$, $\mathrm{Pheo}_{\mathrm{D} 1}$; the plastoquinone acceptor, $\mathrm{Q}_{\mathrm{A}}$; the redox-active tyrosine, $\mathrm{Y}_{\mathrm{Z}}$; and the tetra-nuclear manganese/calcium cluster $\left(\mathrm{Mn}_{4} \mathrm{Ca}\right)$ that is the catalytic site for water oxidation.

Most of the cofactors are within optimal electron tunneling distances $(\sim 10-15 \AA)$ (Moser et al. 1992; Page et al. 1999). Similar to the bacterial reaction center (BRC), there are two possible pathways in the PSII RC for electron transport from the photoactive chlorophyll complex to the quinone acceptors, the left-handed path (or D1-branch) and the right-handed path (or D2-branch).

There are several aspects of PSII electron transport that are important for the efficient oxidation of water. These include: (i) formation and stabilization of the primary radical pair; (ii) the high redox potential of the oxidized primary electron donor; (iii) charge transfer from the primary electron donor to the $\mathrm{Mn}_{4} \mathrm{Ca}$ cluster; (iv) accumulation of oxidizing potential in the $\mathrm{Mn}_{4} \mathrm{Ca}$ cluster; (v) translocation of protons; ( $v i$ ) formation of the $\mathrm{O}-\mathrm{O}$ bond; and (vii) the functional role of the protein suprastructure and dynamics. The following sections briefly address these aspects and point out where future research is needed. For further details, the reader is referred to the references listed in the introduction and to the general review articles in this special issue (see Renger and Renger, Beyaeva et al., Semenov et al., this issue). 


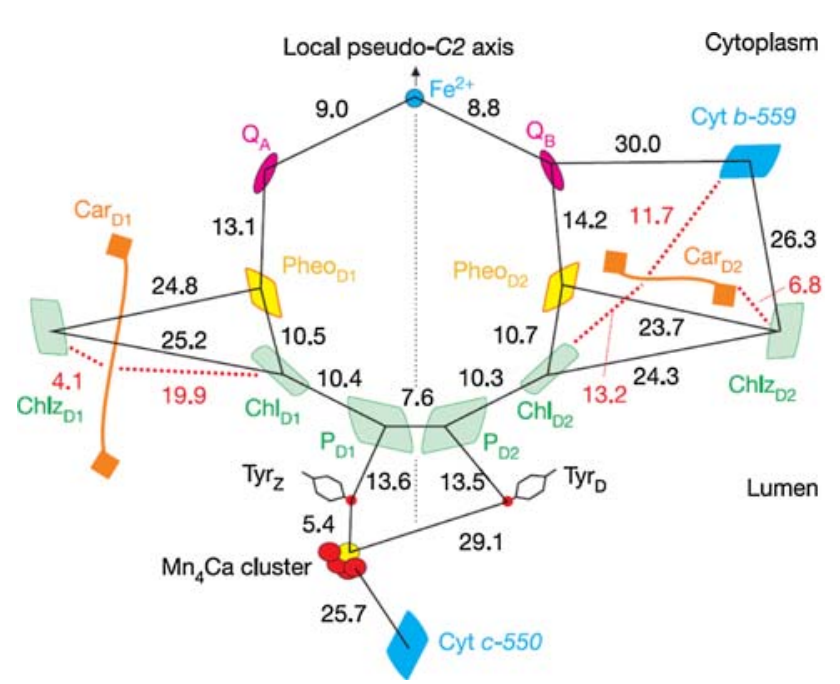

Fig. 1 The relative edge-to-edge distances in Ångstroms between the various cofactors within the Photosystem II core complex (adapted from Loll et al. 2005). In the following notations, the D1 and D2 subscripts refer to a cofactor binding site on either the PsbA or PsbD subunit proteins, respectively. The cofactors include $\mathrm{P}_{\mathrm{D} 1} \mathrm{P}_{\mathrm{D} 2}$, a weakly coupled pair of chlorophyll $a$ molecules; $\mathrm{Ch}_{\mathrm{D} 1}$ and $\mathrm{Ch}_{\mathrm{D} 2}$, two monomeric chlorophylls $a$; $\mathrm{Pheo}_{\mathrm{D} 1}$ and $\mathrm{Pheo}_{\mathrm{D} 2}$, two pheophytins $a ; \mathrm{Q}_{\mathrm{A}}$ and $\mathrm{Q}_{\mathrm{B}}$, the first and second plastoquinone electron acceptors; $\mathrm{Fe}^{+2}$, a non-heme iron; $\mathrm{Car}_{\mathrm{D} 1}$ and $\mathrm{Car}_{\mathrm{D} 2}$, two $\beta$-carotenes; $\mathrm{Chlz}_{\mathrm{D} 1}$ and $\mathrm{Chlz}_{\mathrm{D} 2}$, two special chlorophylls $a$ connecting the reaction center with the proximal light harvesting proteins $\mathrm{CP} 43$ and CP47, respectively; Cyt b-559, cytochrome $b_{559}$; Cyt c-550, cytochrome $c_{550}$; $\mathrm{Tyr}_{\mathrm{Z}}$ and $\mathrm{Tyr}_{\mathrm{D}}$, two redox-active tyrosines; $\mathrm{Mn}_{4} \mathrm{Ca}$, the manganese/calcium cluster. The local pseudo-C2 axis of symmetry divides the cofactors into two possible electron transfer pathways, the left-handed path (or D1-branch) and the right-handed path (or D2-branch)

\section{Formation and stabilization of the primary radical pair}

Unlike the photosynthetic bacteria where the electron hole is initiated and stabilized on the $\mathrm{BChl}_{2}$ special pair, in PSII the exciton is delocalized over the four chlorophylls of the reaction center $(\mathrm{RC})$, i.e., $\mathrm{P}_{\mathrm{D} 1}, \mathrm{P}_{\mathrm{D} 2}, \mathrm{Chl}_{\mathrm{D} 1}$ and $\mathrm{Chl}_{\mathrm{D} 2}$, while the electron is transferred to and stabilized on $\mathrm{Pheo}_{\mathrm{D} 1}$ (see Kálmân et al., this issue). Although charge separation measurements are quite complicated, it is now accepted that the electron hole is initiated on the accessory $\mathrm{Chl}_{\mathrm{D} 1}$ since the $680 \mathrm{~nm}$ bleach, ascribed to the oxidation of the traditional primary electron donor P680, appears after the formation of $\mathrm{PheO}_{\mathrm{D} 1}{ }^{\bullet-}$. The subsequent localization $(\geq 80 \%)$ of the electron hole on $\mathrm{P}_{\mathrm{D} 1}$ gives rise to $\mathrm{P} 680^{\bullet+}$ and displays largely monomeric character (Holzwarth et al. 2006; see Shelaev et al., Khatypov et al., this issue). The formation of the primary radical pair occurs within sub-ps to $\sim 3$ ps at room temperatures, while the appearance of the $\mathrm{P} 680^{\circ+}$ bleach occurs from $\sim 3$ to $\sim 11 \mathrm{ps}$, depending on the sample. Thus, the primary photochemistry in PSII can be illustrated by the following scheme:

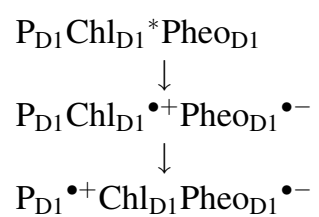

Surprisingly, the charge separation in PSII occurs only along the components of the D1-branch and not the D2branch of the core complex. Why a second pathway exists in PSII and whether it has any function or influence on the charge separation reactions is not known. It could simply be an evolutionary remnant from a longago gene duplication event, although Nature tends not to keep energy-expensive components that are not functional. Based on the current crystal structures, the redox potential of the D2-branch $\mathrm{PheO}_{\mathrm{D} 2}$ was calculated from the charge environment to be about $80 \mathrm{mV}$ lower than the D1-branch $\mathrm{PheO}_{\mathrm{D} 1}$ (Ishikita et al. 2006). If the accessory $\mathrm{Chl}_{\mathrm{D} 1}$ and $\mathrm{Chl}_{\mathrm{D} 2}$ have equivalent potentials, then this could explain why the D1-branch is favored to carry out the electron transport. This interpretation is supported by studies on the modification of the BRC where changes in the charge distribution shift the midpoint potentials significantly and activate the B-branch (see Kálmân et al., this issue). However, the situation in PSII is still ambiguous and depends on the accuracy of the operating potentials and the molecular environment of the cofactors.

The charge separation in PSII is stabilized by the rapid transfer (in about $300 \mathrm{ps)}$ of the electron on the primary electron acceptor $\mathrm{Pheo}^{{ }^{-}-}$to the first plastoquinone acceptor $\mathrm{Q}_{\mathrm{A}}$. The driving force for the forward electron transfer is related to the difference midpoint redox potentials $\left(\Delta E_{\mathrm{m}}\right)$ for the $\mathrm{Pheo}^{\circ}-\mathrm{Q}_{\mathrm{A}}$ couple and should be equivalent to the free energy difference $\left(\Delta G_{0}\right)$. When the $\Delta G_{0}$ for electron transfer from Pheo ${ }^{--}$to $\mathrm{Q}_{\mathrm{A}}$ is determined from the charge recombination reactions, the $\Delta G_{0}$, was found to be significantly lower than the measured $\Delta E_{\mathrm{m}}$ (van Gorkom 1985). This difference between the redox potential and the free energy is largely due to the electrostatic interactions between the oxidized donor and the reduced acceptor (each having a charge of opposite sign). However, there can also be significant interactions with other neighboring charged groups depending on distance. Thus when $\mathrm{P}_{680^{\circ}}{ }^{+}$is present, the transfer of the electron from to $\mathrm{Q}_{\mathrm{A}}$ will be strongly influenced by the $\Delta E_{\mathrm{m}}$ of the $\mathrm{P} 680^{\circ+} / \mathrm{Q}_{\mathrm{A}}{ }^{--}$ couple and the true operating potential will be timedependent (Rappaport and Diner 2008). In order to mimic PSII reactions in artificial systems, it will be necessary to know how the operating potential of each redox cofactor is fine-tuned by its molecular environment. 
High redox potential of the oxidized primary electron donor

The $\Delta E_{\mathrm{m}}$ for the $\mathrm{P} 680^{\circ} / \mathrm{P} 680$ couple as determined from free energy considerations and by measurements of its midpoint potential when referenced to the $\mathrm{Q}_{\mathrm{A}} / \mathrm{Q}_{\mathrm{A}}{ }^{-}$couple $(-0.03 \mathrm{~V})$, is a remarkable $+1.25 \mathrm{~V}$, making the $\mathrm{P} 680^{\circ}+$ radical cation the most oxidizing species in Biology. This high oxidizing potential is essential if water is to be oxidized, which requires an equilibrium redox potential of $\sim+0.82 \mathrm{~V}$ at neutral $\mathrm{pH}$. Since the redox potential for chlorophyll $a$ in solvent is $\sim+0.81 \mathrm{~V}$ vs SHE, the high redox potential of P680 must be due to its binding environment. The factors that are most likely to play a key role in tuning the redox potential of P680 include (i) the extent of electronic coupling between $\mathrm{P}_{\mathrm{D} 1}$ and $\mathrm{P}_{\mathrm{D} 2}$; (ii) the strength and number of hydrogen (H)-bonds; (iii) interactions with neighboring positive charge groups; and (iv) distortion of the planar tetrapyrrole head group. These factors have been elegantly demonstrated in modified BRCs (see Kálmân et al., this issue). One of the challenges for future studies will be to make higher resolution crystal structures and more accurate redox potential determinations to know how interactions with the protein environment regulates the redox potential of each cofactor and to determine whether the inactive D2-branch has any function or influence on the primary charge separation.

A fascinating new aspect in the energetics of the PSII are the recent studies on the oxygenic $\mathrm{Chl} d$-containing cyanobacterium Acharyochloris marina (Chen and Cai 2007; see Cser et al., Ohashi et al., this issue). This organism contains $>95 \% \mathrm{Chl} d$ which absorbs at significantly lower energies than $\mathrm{Chl} a$ (the red Qy absorption band of $\mathrm{Chl} d$ is red shifted out to $740 \mathrm{~nm}$ ). It comprises the light harvesting antenna as well as the PSI reaction center; however, it is still under debate if it also comprises the PSII reaction center. Current studies indicate that both $\mathrm{Chl} a$ and $\mathrm{Chl} d$ are present in the PSII reaction center (Schlodder et al. 2007). If so, it will have important ramifications on the photochemistry needed for oxidation of water.

\section{Charge transfer from the primary electron donor to the $\mathrm{Mn}_{4} \mathrm{Ca}$ cluster}

Because of its very high oxidation potential, the $\mathrm{P} 680^{\circ}+$ radical cation is extremely reactive. If not deactivated by transfer of its charge to the $\mathrm{Mn}_{4} \mathrm{Ca}$ cluster, it will react with the protein matrix or even with $\mathrm{O}_{2}$ itself, generating reactive oxygen species (ROS) such as the hydroxyl radical $\mathrm{OH}^{\bullet}$ or, through charge recombination with the triplet state, create the extremely damaging singlet oxygen, ${ }^{1} \mathrm{O}_{2}$. Such a situation occurs when the efficiency of the $\mathrm{Mn}_{4} \mathrm{Ca}$ cluster break down, e.g., under conditions of environmental stress such as excess light, extreme temperatures, salinity, and water limitation (see Yamamoto et al., Oguchi et al., Allakhverdiev and Murata, Allakhverdiev et al., this issue). PSII has evolved a number of mechanisms to minimize oxidative damage, either by deactivating excess energy before it reaches $\mathrm{P} 680$, by engaging $\mathrm{P}_{680^{\circ}}+$ in a cyclic electron transport path with the acceptor-side, or by quenching ROS intermediates indirectly. The reaction core contains a number of cofactors that function in this capacity, including the $\beta$-carotenes, cytochrome $b_{559}$, and ChlZ. The role of these components in PSII electron transport is actively being studied (see Ivanov et al., Tracewell and Brudvig, Hughes et al., Krieger-Liszkay et al., Litvin et al., Edelman and Matto, this issue).

There are two redox-active tyrosines in PSII, $Y_{D}$, and $\mathrm{Y}_{\mathrm{Z}}$, located in symmetrical positions with respect to the local pseudo $\mathrm{C} 2$ axis (see Mino and Kawamori, this issue). $Y_{D}$ has been identified as D2-Tyr161 and is situated in a hydrophobic environment on the side of the inactive D2branch, while $\mathrm{Y}_{\mathrm{Z}}$ has been identified as D1-Tyr160 and is situated on the side of the active D1-branch very close to the $\mathrm{Mn}_{4} \mathrm{Ca}$ cluster $(\sim 4.2 \AA) . \mathrm{Y}_{\mathrm{Z}}$ mediates the charge transfer from $\mathrm{P}_{680^{\circ}}$ to the $\mathrm{Mn}_{4} \mathrm{Ca}$ cluster. The crystallographic data show that the $\mathrm{Y}_{\mathrm{Z}}$ phenolic hydrogen forms a hydrogen bond (H-bond) with the $\varepsilon$-nitrogen of D1-His190. Because of the low $\mathrm{p} K \mathrm{a}$ for tyrosine radicals, $\mathrm{Y}_{\mathrm{Z}}$ is likely to be de-protonated upon its oxidation. However, the oxidation/reduction reactions of $\mathrm{Y}_{\mathrm{Z}}$ are so fast that an intermediate state has not been spectrally trapped and identified. In addition, the kinetics for the oxidation of $\mathrm{Y}_{\mathrm{Z}}$ is extremely complex, exhibiting several phases with time constants in the sub- $\mu \mathrm{s}, \mu \mathrm{s}$, and tens of $\mu$ s time domains. The fast sub- $\mu$ s phases most likely arise from pure electron transfer, while the slower phases may reflect vibrational relaxation processes of the protein scaffold. For this reason the operating potential for the $\mathrm{Y}_{\mathrm{Z}}{ }^{\mathrm{ox}} / \mathrm{Y}_{\mathrm{Z}}$ couple will be timedependant (Rappaport and Diner 2008).

In the earlier hydrogen-atom abstraction model (Hoganson et al. 1995) it was assumed that $Y_{Z}$ was directly $\mathrm{H}$-bonded to the substrate water. Upon oxidation, $\mathrm{Y}_{\mathrm{Z}}$ would undergo a concerted proton-coupled electron transfer (PCET) where an $\mathrm{H}^{+}$ion is transferred to a nearby base acceptor (i.e., D1-His190) through an exergonic reaction as the electron tunnels to the oxidized $\mathrm{P} 680^{\circ}$. The resulting $\mathrm{Y}_{\mathrm{Z}}{ }^{\bullet}$ radical would then abstract an $\mathrm{H}$-atom from the substrate water bound to the $\mathrm{Mn}_{4} \mathrm{Ca}$ cluster. The experimental support for this hypothesis was based a number of studies but ultimately it was found to be inconsistent with the distances in the crystal structures.

In a more recent proposal the D1-His190 is suggested to bridge $\mathrm{Y}_{\mathrm{Z}}$ to the $\mathrm{Mn}_{4} \mathrm{Ca}$ cluster through a low-barrier hydrogen bond (LBHB) between the tyrosine phenolic 
group and the $\varepsilon$-nitrogen of the histidine (Zhang 2007). The LBHB, being a short, strong H-bond, would lower the activation energy for the oxidation of $\mathrm{Y}_{\mathrm{Z}}$. Thus, $\mathrm{Y}_{\mathrm{Z}}$ would readily give up its electron to $\mathrm{P} 680^{\circ+}$ forming the $\mathrm{Y}_{\mathrm{Z}}{ }^{\text {}}$ radical converting the LBHB to a weak H-bond and thus build up a barrier. In a subsequent reaction an $\mathrm{H}^{+}$ion is released from the substrate water as the $\mathrm{Y}_{Z}{ }^{\bullet}$ is reduced by an electron tunneling from the $\mathrm{Mn}_{4} \mathrm{Ca}$ cluster and the LBHB reforms.

However, the measured kinetic isotope effect (KIE) for the fast phase in the $\mathrm{Y}_{\mathrm{Z}}{ }^{\mathrm{ox}}$ reduction kinetics is very weak (>1.1) (Karge et al. 1997) which is not expected if the substrate water is de-protonated and exchangeable with the solvent. However, the weak KIE plus the fast rate of electron transfer and the apparent low activation energies that is characteristic of $\mathrm{Y}_{\mathrm{Z}}$ oxidation are indicative of $\mathrm{H}$-transfer over short distances via an environmentally coupled H-transfer (ECHT) mechanism (Antoniou and Schwartz 1997). In contrast, the slow kinetic phases in the oxidation of $\mathrm{Y}_{\mathrm{Z}}$ are consistent with the vibrational modes of the protein that promote proton tunneling. In this case, the $\mathrm{H}^{+}$ion tunnels to the acceptor base as the electron tunnels from $\mathrm{Y}_{\mathrm{Z}}$ to $\mathrm{P} 680^{\circ+}$ (see Hay and Scrutton, this issue). To fully understand the mechanism of $Y_{Z}$ function and its ability to mediate the strong oxidizing potential of $\mathrm{P}_{680^{\circ}}{ }^{+}$to the $\mathrm{Mn}_{4} \mathrm{Ca}$ cluster, more information on the atomic structure and local environment of $\mathrm{Y}_{\mathrm{Z}}$ is needed.

\section{Accumulation of oxidation potential in the $\mathrm{Mn}_{4} \mathrm{Ca}$ cluster}

The heart of PSII is the $\mathrm{Mn}_{4} \mathrm{Ca}$ cluster which is the site of the water oxidation reaction. It consists of a bioinorganic core of four $\mathrm{Mn}$ ions that are oxo-bridged, a $\mathrm{Ca}$ ion, the amino acid ligands from the protein scaffold, and the bound substrate water molecules. It is one of the most unique enzymatic catalysts in Nature in that it mediates the one-electron reaction of the primary photochemistry with the four-electron oxidation of water to $\mathrm{O}_{2}$. The different oxidation states through which the $\mathrm{Mn}_{4} \mathrm{Ca}$ cluster cycles to oxidize water is kinetically described by the $\mathrm{Sn}$-state model of Kok et al. (1970) where $n=0,1,2,3$, 4. Thus, the progressive advancement of each S-state is driven by a single light reaction at the PSII RC. Upon reaching the $\mathrm{S}_{4}$ state, $\mathrm{O}_{2}$ is released and the $\mathrm{Mn}_{4} \mathrm{Ca}$ cluster resets to its starting $\mathrm{S}_{0}$ state. By adding chemical reductants Messinger et al. (1997) showed that the $\mathrm{Mn}_{4} \mathrm{Ca}$ cluster can take on negative $\mathrm{S}_{-1}, \mathrm{~S}_{-2}$, and $\mathrm{S}_{-3}$ states, indicating that the starting $\mathrm{S}_{0}$ state has already accumulated three oxidizing equivalents.

A major effort has been made to identify the structure of the $\mathrm{Mn}_{4} \mathrm{Ca}$ catalytic complex which is needed to understand how the oxidizing equivalents are stored and finally combined to oxidize water to molecular $\mathrm{O}_{2}$. Structural determinations began in the late 1970s and early 1980s when the first EPR and EXAFS studies were reported and continue to the present day in which sophisticated techniques such as Mn-ENDOR, polarized XANES/ EXAFS, RIX, X-ray crystallography, and DFT and QM/ MM calculations are used. The multitude of models for the $\mathrm{Mn}_{4} \mathrm{Ca}$ cluster consistent with the spectral data have been reduced to four very similar possibilities, where the four $\mathrm{Mn}$ ions have the same organization and differ only in the position of the $\mathrm{Ca}$ ion and the orientation of the cluster as a whole (Yano et al. 2006). Basically, the four Mn ions are organized as a trimer extended by the fourth $\mathrm{Mn}$ ion as a dangler ion in a $3+1$ configuration. The $\mathrm{Ca}$ possibly bridges the Mn trimer with the Mn dangler.

The $\mathrm{Mn}$ ions in the cluster are connected by di- $\mu$-oxo bridges as well as by ligands to the protein. Based on site directed mutagenesis and the X-ray crystal structures, Asp170, His332, Glu333, and the carboxy terminus of Ala344 of the D1 protein along with Glu354 of the CP43 protein are believed to be amino acids that bind directly to the Mn ions. There are differences of opinion, however, as to whether His337 and Glu189 of the D1 protein are ligands or not. From FTIR measurements, it appears that Asp170 and His332 bind to an Mn ion that does not undergo an oxidation state change during the S-state cycle up to $S_{3}$, while the carboxy terminus of Ala344 appears to bind to an Mn that undergoes an oxidation state change on the $S_{1} \rightarrow S_{2}$ transition. In all cases the amino acid ligands have to be somewhat adjusted in order to make these assignments. It is likely that the positions of the amino acid ligands are shifted due to radiation damage during the X-ray measurements (Yano et al. 2005).

In terms of oxidation states for the individual Mn ions, Mn-ENDOR measurements at X-band and Q-band have demonstrated that for the $S_{0}$ and $S_{2}$ states the distribution of $\mathrm{Mn}$ oxidation states are $\mathrm{Mn}$ (III,III,III,IV) and $\mathrm{Mn}$ (III,IV,IV,IV), respectively. The $S_{2} \rightarrow S_{3}$ transition, however, is still controversial as to whether a metal-centered or a ligand-centered oxidation occurs. The outcome of this controversy will have an important impact on the type mechanism for water oxidation.

Each light reaction at the P680 generates an operating potential of $+1.25 \mathrm{~V}$, which reduces to $+1.2 \mathrm{~V}$ for the $\mathrm{Y}_{\mathrm{Z}}{ }^{\mathrm{ox}}$ / $\mathrm{Y}_{\mathrm{Z}}$ redox couple. In solution, the redox potential for the $\mathrm{O}_{2} /$ $\mathrm{H}_{2} \mathrm{O}$ couple is $+0.815 \mathrm{~V}$ at neutral $\mathrm{pH}$. However, redox potentials will depend on the reaction path. If the oxidation of water occurs in single steps, the redox potential for the first step from water to a hydroxyl radical is $>+2 \mathrm{~V}$, which is a far too high to be accommodated by the oxidizing potential of P680. However, since in PSII the substrate water is bound to the catalytic site and the product $\mathrm{O}_{2}$ is released as a gas, 
the free energy differences between the reactants and products and consequently the redox potential will be smaller. When the concentrations of the substrate and product are taken into consideration, the operating or the configurational potential in PSII is estimated to be $+1.4 \mathrm{~V}$, assuming a concerted four electron reaction (Krishtalik 1990). Although much reduced from the standard potential, the configurational potential still cannot be accommodated by the oxidation potential generated by the primary photochemistry. Thus, there must be other mechanistic factors involved that effectively lower the operating potential for water oxidation. One possibility would be the presence of a strong base acting as a proton-accepting group.

\section{Translocation of protons}

An important aspect in the oxidation of water is the mechanism of proton $\left(\mathrm{H}^{+}\right.$ion) transfer. In the classical mechanism transfer takes place through a transitional state surmounting an activation barrier. In contrast, in proton-coupled electron transfer (PCET) movement of the electron and the proton may occur either consecutively or concertedly. In the first situation, the electron tunnels rapidly through the barrier while the proton moves sluggishly probably via the classical mechanism of transfer. In the second situation, however, the electron and proton move simultaneously. The proton movement is facilitated by coupling to the vibrational modes of the protein, which effectively allows the proton to tunnel through the barrier along with the electron.

The observed proton release pattern for water oxidation to $\mathrm{O}_{2}$ in PSII is $1,0,1,2$ for the $\mathrm{S}_{0} \rightarrow \mathrm{S}_{1}, \mathrm{~S}_{1} \rightarrow \mathrm{S}_{2}$. $\mathrm{S}_{2} \rightarrow \mathrm{S}_{3}$, and the $\mathrm{S}_{3} \rightarrow \mathrm{S}_{4} \rightarrow \mathrm{S}_{0}$ transitions, respectively. The "removal" of $\mathrm{H}^{+}$ions from the catalytic site by binding to a strong bases would not only lower the overall operating potential, but also serve to "level" the midpoint redox potentials for the individual steps. Based on electroluminescence measurements, the midpoint potentials for the $S_{1} / S_{2}, S_{2} / S_{3}$, and $S_{3} / S_{0}$ couples are estimated to be $+1.12,+1.14$, and $+1.08 \mathrm{~V}$, respectively. These values are in range to drive the oxidation of water into $\mathrm{O}_{2}$ and $\mathrm{H}^{+}$ ions. When the proton release is considered along with the removal of the electrons from the $\mathrm{Mn}_{4} \mathrm{Ca}$ cluster, the traditional S-state cycle can be expanded to 9 states where the movement of each electron and proton is considered independently. This has been termed the "I cycle" (Dau and Haumann 2007).

\section{Formation of the $\mathrm{O}-\mathrm{O}$ bond}

There are a large number of proposals for the formation of $\mathrm{O}_{2}$ during water oxidation in PSII (Hillier and Messinger
2005). A general scheme for the arrangement of the catalytic site is given by Renger and Kühn (2007). So far the resolution of the X-ray crystallographic data is too low to identify the binding sites for the substrate water, although they are expected to be located on the $\mathrm{Mn}_{4} \mathrm{Ca}$ cluster. From 18-oxygen isotope exchange measurements using timeresolved membrane inlet mass spectrometry, my lab established that the two substrate molecules bind at different sites in the catalytic complex since their exchange rates vary independently throughout the $\mathrm{S}$ state cycle (see McConnell, Nöring et al., this issue). The slow exchanging substrate can be detected in all $\mathrm{S}$-states through to and including the $\mathrm{S}_{3}$ state and is sensitive to $\mathrm{Ca} / \mathrm{Sr}$ substitution, while the fast-exchanging substrate has been resolved only in the $S_{3}$ and $S_{2}$ states and is invariant to $\mathrm{Ca} / \mathrm{Sr}$ substitution.

These results have led to the group of models for $\mathrm{O}-\mathrm{O}$ bond formation based on a nucleophilic attack mechanism. Basically, one of the substrates is a terminal or bridging oxygen bound to one of the $\mathrm{Mn}$ ions in the $\mathrm{Mn}_{4} \mathrm{Ca}$ cluster. This $\mathrm{Mn}$ ion increases in oxidation state in going from $\mathrm{S}_{1}$ to $\mathrm{S}_{2}$ to $\mathrm{S}_{3}$ [e.g., $\mathrm{Mn}(\mathrm{III})$ to $\mathrm{Mn}(\mathrm{IV})$ to $\mathrm{Mn}(\mathrm{V})$ ], thereby deprotonating the bound substrate oxygen and making it into a strong electrophile. Upon reaching the $\mathrm{S}_{4}$ state, the second substrate oxygen makes a nucleophilic attack on the activated oxygen releasing two protons and forming the $\mathrm{O}-\mathrm{O}$ bond. $\mathrm{O}_{2}$ is released as a new substrate water molecule binds at the catalytic Mn ion. The substrate making the nucleophilic attack could be bound to an $\mathrm{Mn}$ ion that does not change oxidation state or to the $\mathrm{Ca}$ ion or to the protein scaffold (for details, see Hillier and Messinger 2005).

In the second group of models, a radical mechanism is invoked. In this case a ligand centered oxidation at a bridging oxygen in the $\mathrm{Mn}_{4} \mathrm{Ca}$ cluster occurs in the $\mathrm{S}_{3}$ state forming a delocalized radical. Upon advancing to the $\mathrm{S}_{4}$ state, a second radical forms either at another bridging oxygen or at a terminal oxygen. Condensation of the two radicals forms the $\mathrm{O}-\mathrm{O}$ bond as new substrate water molecules replace the bridging oxygens. In this case the $\mathrm{Mn}_{4} \mathrm{Ca}$ cluster temporarily breaks apart and the bridging oxygens are at first protonated (for details, see Hillier and Messinger 2005).

Alternatively, the $\mathrm{O}-\mathrm{O}$ bond may have formed in the $\mathrm{S}_{3}$ state as abound peroxide intermediate, although there is increasing evidence for a distinct intermediate in the $\mathrm{S}_{4}$ state (see Clausen and Junge, this issue).

\section{The functional role of proteins}

The protein infrastructure provides not only a scaffold to position the cofactors, but also tunes the properties of each cofactor in order to optimize the reactions (see Satoh, Mulo et al., Luo and Eaton-Rye, Iida et al., Rose et al., Takano et al., this issue). Indeed, the discovery of $\mathrm{Y}_{\mathrm{Z}}$ in PSII was 
the first example in which a component of the protein backbone participated directly in electron transport. A very important set of proteins in PSII that optimizes the yield of $\mathrm{O}_{2}$ production are the so-called extrinsic proteins (see Enami et al., this issue). There is some variation in these proteins between the prokaryotic cyanobacteria and the eukaryotic algae and higher plants, where the PsbV (i.e., the cytochrome $c_{550}$ ) and PsbU proteins are found in the prokaryotes and the PsbP and PsbQ proteins in the eukaryotes. These extrinsic proteins may be involved in regulating the ionic environment around the catalytic site. However, the extrinsic protein that seems to be universally present in all oxygenic photosynthetic organisms is the PsbO or manganese stabilizing protein (MSP) (see Williamson, Lundin et al., Nikitina et al., this issue). The function of this protein appears to be to shield the $\mathrm{Mn}_{4} \mathrm{Ca}$ catalytic cluster from the bulk aqueous solution phase. Upon its removal, the $\mathrm{Mn}_{4} \mathrm{Ca}$ becomes unstable and falls apart. Presumably by exposing the catalytic site to the aqueous solvent phase, secondary redox reactions lead to the reduction of the bound manganese to $\mathrm{Mn}$ (II), which can no longer maintain its bridging ligands.

If the primary function of the MSP is to shield the $\mathrm{Mn}_{4} \mathrm{Ca}$ catalytic cluster from the aqueous phase, then there must be a limited access of the substrate water to its binding sites in the catalytic cluster. Exposure to "too much" water may result in deleterious side reactions by short circuiting of the S-state cycle and releasing ROS (see Semin et al., this issue). The limited access of the substrate water may be an important feature for $\mathrm{O}-\mathrm{O}$ bond formation, particularly in the nucleophilic attack mechanism where there would be an ordered binding of the two substrate molecules to insure O-O bond formation (Wydrzynski et al. 1996). As such there may be specific substrate water channels through the protein matrix of PSII. There is accumulating theoretical and experimental evidence for the existence of specific channels in proteins for small molecules including water, $\mathrm{O}_{2}$ and $\mathrm{H}_{2}$ (Cohen et al. 2005; see Hamdane et al., this issue). Recent computational analysis of the current crystallographic structures of PSII has revealed several possible channels from the $\mathrm{Mn}_{4} \mathrm{Ca}$ catalytic cluster to the surface (see Ho, this issue). However, an experimental attempt to highlight these channels in the structure of PSII by xenon doping of the crystals was unsuccessful because of the low resolution of the present structural data (see Murray et al., this issue). This aspect of PSII promises to be a major area of research in the future.

\section{Concluding remarks}

As evidenced by this special issue of Photosynthesis Research, we know quite a lot about PSII and the water oxidation reaction. However, there are still many questions to be answered. It is clear that the structural features and dynamics of the protein scaffold in PSII are critical for the efficient electron transfer which leads to the oxidation of water to molecular $\mathrm{O}_{2}$. However, to fully understand these protein interactions, higher resolved crystal structures as well as methods to determine protein dynamics will be needed. Another approach for understanding PSII structure and function may be through the directed evolution of core complex components where important features may be identified and modified (see Müller-Cajar and Whitney, this issue). Alternatively, it may also be useful to study simpler versions of the PSII core. The application of molecular engineering to modify proteins is now well established (see Razeghifard, Conlan, this issue) and the next steps in PSII research could include the reverse engineering of PSII components into well-defined model proteins that can be used for the various spectroscopic and biophysical measurements. We have started in this research direction and have modified the well-characterized bacterioferritin protein from E. coli, to undergo photochemical reactions by building in a basic quinone-pigment-tyrosinemanganese motif. With this simpler system we will be able to systematically adjust the protein to take on PSII properties (see Conlan, this issue). The unique feature of bacterioferritin to form a hollow, spherical nanostructure may be used to compartmentalize various reactions. The ultimate goal would be to split water into $\mathrm{O}_{2}$ and $\mathrm{H}_{2}$ within the same molecular assembly. Regardless, the future research in PSII promises to be an exciting challenge.

Acknowledgments There are so many people with whom I have worked and who have been an inspiration to me throughout my career that I can only acknowledge a few of them here. Certainly Govindjee has always provided me with support and understanding without which I would not have undertaken the "unbeaten path" that Henry David Thoreau so intensely espoused at Walden Pond. And I certainly wish to sincerely thank all of my colleagues and friends who provided the recollections in Govindjee's article in this Special Issue, which brought back so many fond memories. I would like to especially acknowledge Warwick Hiller, who has not only been a keen collaborator, but also a good mate, and the postdocs and graduate students whom I have had the privilege to work with at the Australian National University: Johannes Messinger, Christiane Funk, Karin Åhrling, Reza Razeghifard, Haoming Zhang, Garth Hendry, Sam Hay, Brett Wallace, Iain McConnell, Adele Williamson, and Brendon Conlan. Finally, I wish to sincerely thank Suleyman Allakhverdiev for not only putting together such an outstanding special issue on Photosystem II, but also for his patience and understanding of all the problems that $\mathrm{I}$ caused in getting this issue on time.

\section{References}

Allakhverdiev SI, Aro E-M, Klimov VV, Nagata T, Satoh K, Shuvalov VA, Telfer A, Wydrzynski T (eds) (2007) Special issue: structure and function of the photosystems. Biochim Biophys Acta 1767(6):401-882. doi:10.1016/j.bbabio.2007.01.002 
Antoniou D, Schwartz SD (1997) Large kinetic isotopic effects in enzymatic proton transfer and the role of substrate oscillations. Proc Natl Acad Sci USA 94:12360-12365. doi:10.1073/pnas.94. 23.12360

Carpentier R, Allakhverdiev SI (eds) (2005) Special issue: photosynthesis and the Post-Genomic Era: from biophysics to molecular biology, a path in the research of Photosystem II. Photosynth Res 84:1-372. doi:10.1007/s11120-005-6714-3

Barber J, Anderson JM (eds) (2002) Special issue: Photosystem II: molecular structure and function. Philos Trans Roy Soc, Ser B 357(1246):1321-1512

Barber J, Rutherford AW (eds) (2008) Discussion meeting issue: revealing how nature uses sunlight to split water. Philos Trans Roy Soc, Ser B 363(1494):1125-1303

Barry BA, Brucker T (eds) (2002) Special issue: biochemistry of the photosynthetic water oxidizing complex. Photosynth Res 72(2): 123-222

Brudvig GW (ed) (2008) Role of manganese in photosystem II. Coord Chem Rev 252:231-468

Chen M, Cai Z-L (2007) Theoretical study on the thermodynamic properties of chlorophyll d-peptides coordinating ligand. Biochim Biophys Acta 1767:603-609. doi:10.1016/j.bbabio.2007. 01.006

Cohen J, Kim K, Posewitz M, Ghirardi ML, Schulten K, Seibert M, King P (2005) Molecular dynamics and experimental examination of $\mathrm{H}_{2}$ and $\mathrm{O}_{2}$ diffusion in [Fe]-hydrogenase. Biochem Soc Trans 33:80-82. doi:10.1042/BST0330080

Dau H, Haumann M (2007) Eight steps preceding O-O bond formation in oxygenic photosynthesis - a basic reaction cycle of the Photosystem II manganese complex. Biochim Biophys Acta 1767:472-483. doi:10.1016/j.bbabio.2007.02.022

Döring G, Renger G, Vater J, Witt HT (1969) Properties of the photoactive chlorophyll-a $\mathrm{a}_{\text {II }}$ in photosynthesis. Z Naturforsch [B] 24b:1139-1143

Duysens LNM, Sweers HE (1963) Mechanism of two photochemical reactions in algae studied by means of fluorescence. In: Japanese of Plant Physiologists (ed) Studies on microalgae and photosynthetic bacteria. Univ Tokyo Press, Tokyo, pp 353-372

Eisenberg R, Gray HB (eds) (2008) Special issue: Forum on Making Oxygen. Inorg Chem 47(60):1697-2232. doi:10.1021/ic800155g

Ferreira K, Iverson TM, Maghlouni K, Barber J, Iwata S (2004) Architecture of the photosynthetic oxygen-evolving center. Science 303:1831-1838. doi:10.1126/science.1093087

Hankamer B, Morris E, Nield J, Gerle C, Barber J (2001) Threedimensional structure of the Photosystem II core dimer of higher plants determined by electron microscopy. J Struct Biol 135:262-269. doi:10.1006/jsbi.2001.4405

Hoganson CW, Lynakis-Simantiris N, Tang XS, Tommos C, Warncke K, Babcock GT, Diner BA, McMracken J, Styring S (1995) A hydrogen-atom extraction model for the function of $\mathrm{Y}-\mathrm{Z}$ in photosynthetic oxygen evolution. Photosynth Res 46:177-184. doi: $10.1007 / \mathrm{BF} 00020428$

Holzwarth AR, Muller MG, Reus M, Nowaczyk M, Sander J, Rögner $M$ (2006) Kinetics and mechanism of electron transfer in intact Photosystem II and in the isolated reaction center: pheophytin is the primary electron acceptor. Proc Natl Acad Sci USA 103:6895-6900. doi:10.1073/pnas.0505371103

Hillier W, Messinger J (2005) Mechanism of photosynthetic oxygen production. In: Wydrzynski T, Satoh K (eds) Photosystem II: the light-driven water:plastoquinone oxidoreductase. Springer, Dordrecht, pp 567-608

Ishikita H, Biesiadka J, Loll B, Saenger B, Knapp E-W (2006) Cationic state of accessory chlorophyll and electron transfer through pheophytin to plastoquinone in Photosystem II. Angew Chem 45:1964-1965. doi:10.1002/anie.200503804
Joliot P, Barbieri G, Chabaud R (1969) Un nouveaux modele des centres photochimiques du système II. Photochem Photobiol 10:309-329. doi:10.1111/j.1751-1097.1969.tb05696.x

Karge M, Irrgang K-D, Renger G (1997) Analysis of the reaction coordinate of photosynthetic water oxidation by kinetic measurements at $355 \mathrm{~nm}$ absorption changes at different temperatures in Photosystem II preparations suspended in either $\mathrm{H}_{2} \mathrm{O}$ or $\mathrm{D}_{2} \mathrm{O}$. Biochemistry 36:8904-8913. doi:10.1021/bi962342g

Kok B, Forbush B, McGloin M (1970) Cooperation of charges in photosynthetic $\mathrm{O}_{2}$ evolution. Photochem Photobiol 11:457-476. doi:10.1111/j.1751-1097.1970.tb06017.x

Krishtalik LI (1990) Activation energy of photosynthetic oxygen evolution: an attempt at theoretical analysis. Bioelectrochem Bioenerg 23:249-263. doi:10.1016/0302-4598(90)80014-A

Loll B, Kern J, Saenger W, Zouni A, Biesiadka J (2005) Towards complete cofactor arrangement in the $3.0 \mathrm{~A}$ resolution structure of Photosystem II. Nature 438:1040-1044. doi:10.1038/nature 04224

Messinger J, Lubitz W (eds) (2004) Special issue: biophysical studies of Photosystem II and related model systems. Phys Chem Chem Phys 6(20):4733-4912. doi:10.1039/b406437b

Messinger J, Seaton G, Wydrzynski T, Wacker U, Renger G (1997) S-3 state of the water oxidase in Photosystem II. Biochemistry 36:6862-6873. doi:10.1021/bi962653r

Moser C, Keske JM, Warncke K, Farid RS, Dutton PL (1992) Nature of biological electron-transfer. Nature 355:796-802. doi:10.1038/ $355796 \mathrm{a} 0$

Nugent J (ed) (2001) Special issue: photosynthetic water oxidation. Biochim Biophys Acta-Bioenerg 1503(1-2):1-259

Page CC, Moser CC, Chen XX, Dutton PL (1999) Natural engineering principles of electron tunnelling in biological oxidationreduction. Nature 402:47-52. doi:10.1038/46972

Putnam-Evans C, Barry BA (eds) (2007) Special issue: photosynthetic water oxidation. Photosynth Res 92(3): 273-425

Rappaport F, Diner BA (2008) Primary photochemistry and energetics leading to the oxidation of the $(\mathrm{Mn})_{4} \mathrm{Ca}$ cluster and to the evolution of molecular oxygen in Photosystem II. Coord Chem Rev 252:259-272. doi:10.1016/j.ccr.2007.07.016

Renger G (ed) (2008) Primary processes of photosynthesis: principles and apparatus, parts 1 and 2. RSC Publishing, UK

Renger G, Kühn P (2007) Reaction pattern and mechanism of light induced oxidative water splitting in photosynthesis. Biochim Biophys Acta 1767:458-471. doi:10.1016/j.bbabio.2006.12.004

Schlodder E, Çetin M, Eckert H-J, Schmitt F-J, Barber J, Telfer A (2007) Both chlorophylls $a$ and $d$ are essential for the photochemistry in Photosystem II of the cyanobacteria Acaryochloris marina. Biochim Biophys Acta Bioenerg 1747:589595. doi:10.1016/j.bbabio.2007.02.018

Stiehl HH, Witt HT (1969) Quantitative treatment of the function of plastoquinone in photosynthesis. Z Naturforsch [B] 24b: $1588-1598$

van Gorkom HJ (1974) Identification of the reduced primary electron acceptor of Photosystem II as a bound semiquinone anion. Biochim Biophys Acta 347:439-442. doi:10.1016/0005-2728(74) 90081-4

van Gorkom H (1985) Electron transfer in Photosystem II. Photosynth Res 6:97-112. doi:10.1007/BF00032785

Wydrzynski T (1981) Oxygen evolution in photosynthesis, Chapter 10. In: Govindjee (ed) Photosynthesis-energy conversion by plants and bacteria, vol I. Academic Press, New York, pp 469-506

Wydrzynski T, Satoh K (eds) (2005) Photosystem II-the light-driven water:plastoquinone oxidoreductase. In: Govindjee (series ed) Advances in photosynthesis and respiration, vol 22. Springer, Dordrecht 
Wydrzynski T, Hillier W, Messinger J (1996) On the functional significance of substrate accessibility in the photosynthetic water oxidation mechanism. Physiol Plant 96:342-350. doi:10.1111/ j.1399-3054.1996.tb00224.x

Wydrzynski T, Hillier W, Conlan B (2007) Engineering model proteins for Photosystem II function. Photosynth Res 94:225233. doi:10.1007/s11120-007-9271-0

Yano J, Kern J, Irrgang K-D, Latimer MJ, Bergmann U, Glatzel P, Pushkar Y, Biesiadka J, Loll B, Sauer K, Messinger J, Zouni A, Yachandra VK (2005) X-ray damage to the $\mathrm{Mn}_{4} \mathrm{Ca}$ complex in single crystals of Photosystem II: a case study for metalloprotein crystallography. Proc Natl Acad Sci USA 102:12047-12052. doi:10.1073/pnas.0505207102

Yano J, Kern J, Sauer K, Latimer JM, Pushkar Y, Biesiadka J, Loll B, Saenger W, Messinger J, Zouni A, Yachandra VK (2006) Where water is oxidized to dioxygen: structure of the photosynthetic $\mathrm{Mn}_{4} \mathrm{Ca}$ cluster. Science 314:821-825. doi:10.1126/science.112 8186

Zhang C (2007) Low-barrier hydrogen bond plays key role in active Photosystem II-a new model for photosynthetic water oxidation. Biochim Biophys Acta 1757:493-499 